\title{
HEGEL Y LACAN, O LA BÚSQUEDA DEL SENTIDO
}

Jaime CAstillo

Pontificia Universidad Católica del Perú

El presente trabajo es un intento de aproximación crítica -desde la propia lógica del sistema- a la supuesta visión teleológica presente en la concepción hegeliana de la ética. En primer lugar, analizaremos este componente teleológico y mostraremos cómo la imposibilidad de una realización fáctica en la propia dimensión del espíritu objetivo de este supuesto telos conlleva a una redefinición total del recorrido del mismo. En segundo lugar, en tanto la nueva figura aparece carente de dirección y reclama, a lo sumo, su consumación en una dimensión distinta a la fáctica, se hace necesario introducir algún elemento que nos permita sostener el recorrido del espíritu objetivo; es en este punto que arribamos a la noción lacaniana de "sentido", la cual estudiaremos tanto en su significación original (es decir, entendiendo "sentido" como despliegue masivo de significantes cuyo único orden es una dirección) como en su particularización mediante la figura del "sentido ético". La parte final de nuestro trabajo estará dedicada a examinar las consecuencias que tiene nuestro intento de síntesis para una real comprensión del fenómeno ético.

Palabras clave:

Hegel, Lacan, sentido, ética, significante 


\section{Nota introductoria}

El presente texto se divide en tres partes y cada una de ellas en tres secciones. La primera parte se titula "Hegel y la teleología" y explora el problema de la teleología en la filosofía práctica de dicho autor. Inicia por una breve exposición del lugar que ocupa la filosofía práctica en el sistema hegeliano (primera sección: "La filosofía del espíritu objetivo") que nos permite llegar a la figura del Estado como consumación de la misma, la cual determina el paso hacia la siguiente fase del espíritu: el absoluto (segunda sección: "El Estado y el paso al absoluto"); finalmente exponemos lo que consideramos como la paradoja de la teleología (tercera sección: "La destrucción de la teleología). En la segunda parte, titulada "Lacan y el sentido", exploramos la obra de Lacan para arribar a la noción de sentido como nueva manera de sostener el recorrido del espíritu objetivo. Iniciamos exponiendo la concepción de signo que plantea Lacan en la sección "Lacan y la reflexión lingüística”, para luego llegar a definir el sentido en sus distintos aspectos (segunda sección: "La noción de sentido") y llegar al símil fundamental que nos traerá de vuelta a la filosofía de Hegel, en la sección titulada "La autopista". La parte final de nuestro trabajo explora ciertas posibilidades lógicas del sentido (primera sección: “La función sentido”) para aplicarlas al terreno de la ética en la segunda sección: "El sentido de la ética", finalmente, explicitamos la correspondencia entre las teorías de ambos autores en la última sección: "Hegel y Lacan”.

Respecto a las fuentes empleadas, la primera se basa en los textos del propio Hegel: la Enciclopedia de las ciencias filosóficas, los Principios de la filosofía del derecho, la Ciencia de la lógica y las Lecciones sobre la filosofía de la historia universal. Para la segunda parte, hemos empleados los Seminarios III, VII y XX de Lacan. Además de los textos lacanianos, se emplea el Curso de lingüística general de Ferdinand de Saussure, y las interpretaciones de ambos de Jean Claude Milner presentes en su libro El periplo estructural y de Mario Montalbetti 
contenidas en sus libros Lacan arquitectura y Cajas, en la conferencia "Autopista, corredor y sentido" y en algunas comunicaciones personales. Para cierta interpretación de la obra de Hegel en relación con Lacan nos son útiles los textos de Slavoj Žižek "Lacan: at What Point is He Hegelian?" y "Is it posible to be a Hegelian today?" Otros textos que se mencionan muy brevemente en este trabajo son los textos éticos de Aristóteles y de Kant, las obras de Freud y el Tractatus logicus philosophicus de Wittgenstein.

\section{§ 1. Hegel y la teleología}

\section{$\S$ I.I. La filosofía del espíritu objetivo}

Este es el sistema hegeliano tal como se encuentra desarrollado en la Enciclopedia de las ciencias filosóficas':

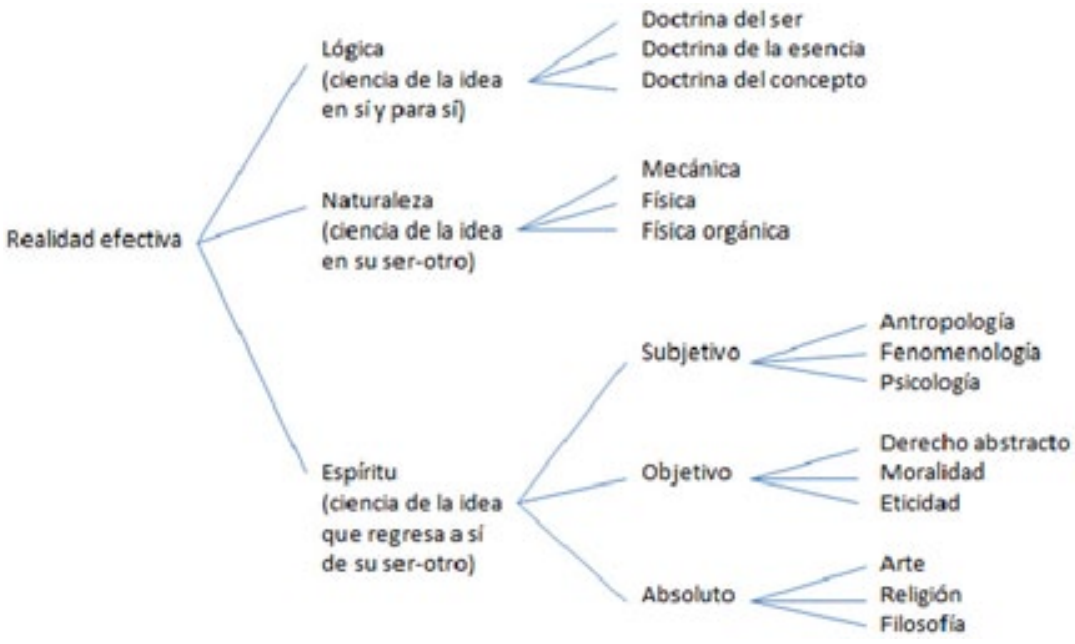

La parte que nos ocupa es la correspondiente al espíritu objetivo, de él la eticidad, de ella el Estado. "La filosofía del espíritu es la ciencia de la idea que regresa a sí desde su ser-otro [la naturaleza]”2.

\footnotetext{
I Hegel, G.W.F. Enciclopedia de las ciencias filosóficas en compendio (para uso de sus clases), traducción de Ramón Valls Plana, Madrid: Alianza Editorial, 1997.

2 Ibid., § I8, p. 120.
} 
El desarrollo del espíritu comprende tres etapas: subjetivo, objetivo y absoluto.

a) En la primera fase el espíritu "está en la forma de la referencia a sí mismo; dentro de sí le deviene la totalidad ideal de la idea (...): espíritu subjetivo".

b) "[En el espíritu objetivo] está en la forma de la realidad, como un mundo que desde él se ha de producir y se ha producido, y en el que la libertad está como necesidad presente (...)".

c) En la tercera fase "está en la unidad de su objetividad y su idealidad o concepto, unidad que dentro de él está-siendo en sí y para sí y que está produciéndose eternamente; es el espíritu en su verdad absoluta: el espíritu absoluto"3.

Hegel dice que las dos primeras formas corresponden al espíritu finito, entendiendo finitud como "la inadecuación del concepto y la realidad", mientras que la última al espíritu en su infinitud, v.g., en su total adecuación consigo mismo. Tanto el espíritu subjetivo como el objetivo, por lo tanto, carecen de algo, de una determinación fundamental que completan en el absoluto.

Volvamos al espíritu objetivo: "El terreno del derecho es lo espiritual; su lugar más preciso y su punto de partida es la voluntad, que es libre, de modo tal que la libertad constituye su sustancia y determinación, y el sistema del derecho es el reino de la libertad realizada, el mundo del espíritu que se produce a partir de sí mismo como una segunda naturaleza”s.

La figura distintiva del espíritu objetivo y que subraya el volcarse del espíritu hacia un mundo exterior es la voluntad y su determinación esencial es la de ser libre; al término del recorrido, hacia el momento en el que el espíritu objetivo habrá de reconciliarse con el infinito, la voluntad habrá alcanzado su total libertad, dicha libertad se alcanza en la eticidad. En la eticidad: "La voluntad es la idea pensada del bien, realizada en la voluntad reflejada en sí misma y en el mundo exterior, de manera tal que la libertad, en cuanto sustancia, existe como realidad y necesidad y al mismo tiempo como voluntad subjetiva; la idea en su existencia universal en y por sí”.

3 lbid., § 385, p. 437. Las tres citas se encuentran en la misma página y en el mismo parágrafo.

4 lbid., § 386, p. 438.

5 Hegel, G.W.F. Principios de la filosofía del derecho o derecho natural y ciencia política, traducción de Juan Luis Vermal, Barcelona: Edhasa, 1999, § 4, p. 77.

6 Ibid. § 33, p. II 2. 
La eticidad, dice Hegel en la Enciclopedia, es "el cumplimiento del espíritu objetivo, la verdad del espíritu subjetivo y objetivo mismo"7, y en la Filosofía del derecho: "la idea de la libertad como bien viviente que tiene en la autoconciencia su saber, su querer y, por medio de su actuar, su realidad (...). Es el concepto de la libertad que ha devenido mundo existente y naturaleza de la autoconciencia"8. En la eticidad culmina el recorrido del espíritu objetivo, en

ella aparece la tercera determinación del concepto hegeliano: la singularidad, luego de aparecidas la universalidad del derecho abstracto y la particularidad de la moralidad.

\section{$\S$ I.2. El Estado y el paso al absoluto}

La síntesis lograda en la eticidad halla su consumación en la tercera figura de la misma: el Estado. Hegel define al Estado como "la sustancia autoconsciente como espíritu desarrollado hasta una realidad orgánica efectiva" y como "la realidad efectiva de la idea ética, el espíritu ético como voluntad sustancial revelada, clara para sí misma, que se piensa y se sabe y cumple aquello que sabe precisamente porque lo sabe"10.

Hegel encuentra en el Estado la síntesis de momentos anteriores.

i) La antigua polis griega, tan cara a nuestro autor en sus primeros escritos, y la sociedad civil moderna, como producto histórico ineludible. EI Estado, a entender de Hegel, trae de vuelta la noción de pertenencia venida a menos con la modernidad, con el surgimiento de lo que Arednt llamaría "esfera social"", sin descuidarla.

ii) La ley estatal, plasmada en la Constitución (entendida esta como la expresión del espíritu del pueblo) incluye en ella la determinación de exterioridad del derecho abstracto, así como la autoconciencia de la ley expuesta en la moralidad.

iii) El Estado es la culminación lógica del espíritu objetivo: la reconciliación entre individuo y comunidad, entre derecho y deber, finalmente, entre

7 Hegel, G.W.F., Enciclopedia, §5I3, p. 538.

8 Hegel, G.W.F., Principios de la filosofía del derecho, § 142, p. 265.

9 Hegel, G.W.F., Enciclopedia, § 5I7, p. 540.

10 Hegel, G.W.F., Principios de la filosofía del derecho, § 257, p. 370.

"Cf. Arendt, Hannah, La condición humana, Barcelona: Seix Barral, 1974, ver sección II ("La esfera pública y la privada"), pp. 39-109. 
sustancia y sujeto, como anunciaba el Prólogo de la Fenomenología del espíritu'2.

Hegel ha mencionado, además, el carácter orgánico del Estado, "realidad orgánica efectiva" dice la definición de la Enciclopedia. El Estado no reconoce en el terreno práctico ninguna ley más que la suya, de ahí la desconfianza de Hegel ante los tratados de paz y su consideración de la guerra como factor positivo para el sostenimiento de la eticidad. El Estado es ya racional, la voluntad es ya libre: el espíritu objetivo ha concluido su recorrido. Pero existe una dimensión más que el filósofo considera el último momento del Estado: la historia universal.

La historia universal se eleva como la única esfera a la cual el Estado se "subordina": "En su relación recíproca, sus destinos y actos constituyen la manifestación de la dialéctica de la finitud de esos espíritus [de los Estados], de la que surge, ilimitado, el espíritu universal, el espíritu del mundo, que es al mismo tiempo quien ejerce sobre ellos su derecho-y su derecho es el derecho supremo- en la historia universal, erigida en tribunal universal"'3.

Además, la historia universal determina el paso del espíritu objetivo al absoluto: "Este movimiento es el camino de la liberación de la sustancia espiritual; es el acto por medio del cual se lleva a cabo el último fin absoluto del mundo en el mundo"14; "Pero el espíritu pensante de la historia universal en tanto se despoja al mismo tiempo de aquellas limitaciones [que son] propias de los espíritus particulares de los pueblos y de su propia mundanidad, comprende su universalidad concreta y se eleva al saber del espíritu absoluto, como saber de la vida eternamente real y efectiva" "5; "El elemento en que existe el espíritu universal, que en el arte es la intuición y la imagen, en la religión el sentimiento y la representación, en la filosofía el pensamiento libre y puro, es en la historia universal, la realidad espiritual en toda la extensión de su interioridad y de su exterioridad"16.

${ }^{12}$ Hegel, G.W.F., Fenomenología del espíritu, traducción de Wenceslao Roces, México: FCE, 2008, p. 15 ss.

${ }^{13}$ Hegel, G.W.F., Principios de la filosofía del derecho, §340, p. 489.

14 Hegel, G.W.F., Enciclopedia, § 549, p. 566.

15 Ibid. § 552, p. 57I.

${ }^{16}$ Hegel, G.W.F., Principios de la filosofía del derecho, § 34I, pp. 489-490. 
Estas formulaciones son expuestas también en las Lecciones sobre la filosofía de la historia universal, donde Hegel expone detalladamente estas cuestiones así como los cuatro mundos mencionados hacia el final de la Filosofía del derecho. Pero algo señala Hegel en estas Lecciones: la presencia de un fin en la historia. "El fin de la historia universal es (...) que el espíritu llegue a saber lo que es verdaderamente $y$ haga objetivo este saber, lo realice en un mundo presente, se produzca a sí mismo objetivamente"|7. Confrontemos esta cita que empieza a insinuar una teleología en el propio seno de lo objetivo con el primer parágrafo de la sección correspondiente al espíritu absoluto en la Enciclopedia: "El concepto del espíritu tiene su realidad en el espíritu. Que esta realidad, en su identidad con el concepto, sea como saber de la idea absoluta, he ahí el lado necesario, esto es, que la inteligencia, libre en sí, sea liberada en su realidad efectiva hasta [alcanzar] su concepto para que sea [así] figura digna de él. El espíritu subjetivo y el objetivo han de verse como el camino por el que se forma este lado de la realidad o de la EXISTENCIA"|8.

¿Qué tipo de fin(alidad) tiene la historia? ¿Se la está entendiendo como elemento del espíritu absoluto o se la concibe en su materialidad fáctica?

\section{§ I.3. La destrucción de la teleología}

La cuestión de la teleología es tratada por Hegel en los parágrafos 204-2I 2 de la Enciclopedia y en el tercer capítulo de la segunda sección ("La objetividad”) del tercer libro (“Doctrina del concepto”) de la Ciencia de la lógica. Retengamos la contraposición entre mecanismo y teleología: "[ella] se contrapone al mecanismo, donde la determinación, puesta en el objeto, es esencialmente, como extrínseca, una determinación tal que en ella no se manifiesta ninguna autodeterminación"|9. Dado ello, al espíritu le cabría una dimensión teleológica, no mecanicista, el espíritu tiene como finalidad autodeterminada el conocimiento de sí mismo (libertad en la necesidad).

\footnotetext{
17 Hegel, G.W.F., Lecciones sobre la filosofía de la historia universal, traducción de José Gaos, Madrid: Revista de Occidente, 1974, p. 76

18 Hegel, G.W.F., Enciclopedia, § 553, p. 580.

19 Hegel, G.W.F., Ciencia de la lógica, traducción de Augusta y Rodolfo Mondolfo, Buenos Aires: Solar, 1968, p. 647.
} 
Volvamos a la pregunta por el tipo de fin(alidad) de la historia. El espíritu objetivo es solo una fase en el desarrollo del espíritu, una fase finita que requiere de una segunda negación para alcanzar su fase infinita: el absoluto. El espíritu absoluto se realiza en la historia, esta es su terreno. iHay una teleología en la sucesión histórica fáctica? Esto implicaría asumir que hay alguna formación dentro del propio espíritu objetivo, una realidad institucional que sintetiza todo el recorrido del mismo: esto es imposible, pues el espíritu absoluto solo se alcanza en una suerte de puesta entre paréntesis de la realidad objetiva (en el sentido hegeliano), la cual conllevaría a alcanzar al absoluto, como intuición, representación o pensamiento puro (arte, religión o ciencia).

Asumamos la idea hegeliana de que el Estado es el protagonista de la historia universal presente en las Lecciones (esto es, evidentemente, una simplificación). Dado lo señalado anteriormente, la historia aparece como una sucesión de realidades ético-políticas que tienen como telos el autoconocimiento del espíritu, pues la historia es el elemento del espíritu absoluto. Este telos se realiza, forzosamente, en una dimensión distinta de la fáctica, el absoluto no es un peldaño más en la línea de la historia, no hay un último Estado.

El gráfico de una historia entendida a la manera teleológica (en su propia dimensión) sería:

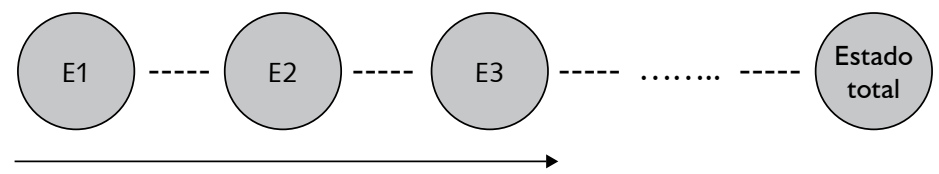

La flecha indica la dirección de la historia. Según este gráfico la historia se mueve hacia la aparición, en la propia dimensión del espíritu objetivo, de un Estado último, de una realidad efectiva que es en sí misma absoluta. Sin, embargo, como hemos señalado, los rasgos estudiados del Estado, tanto en términos particulares como en términos de su relación con el sistema, impiden asumir que exista una distinción de este tipo, que alguno de los momentos sea "más absoluto" que el otro, cosa distinta es la afirmación de Hegel de que unos son más racionales que otros: "Todo Estado, aunque por los principios que posee se lo declare malo o se reconozcan en él determinadas carencias, tiene en su 
interior los momentos esenciales de su existencia, especialmente si pertenece a los Estados civilizados de nuestra época"20.

La imposibilidad de concebir un término del devenir histórico o, al menos, la supremacía de cierto tipo de Estado determina que la historia aparezca carente de dirección en su propio ámbito, que el absoluto sea lo único que une los distintos momentos de la historia, pero ¿hacia dónde?

La situación se agrava si renunciamos al absoluto o si lo consideramos, como hará Žižek, como "la falta del Otro", como un hueco que hace las veces del Das Ding freudiano. Žižek habla de "la cosa hegeliana", de aquella dimensión que resulta "tenebrosa y ridícula" para el pensamiento poshegeliano, pero que no es sino la propia captación del devenir y, consiguientemente, de la falla, que no involucra completud alguna ${ }^{21}$.

Queda reconstruir el sistema desde este nuevo punto de vista, recomponer el recorrido del espíritu objetivo, hallarle una lógica a la historia que no sea ni la consumación definitiva en algún punto determinado ni la búsqueda cosificante de una tercera dimensión además de la objetiva y la subjetiva. Resta, pues, salir en busca del sentido.

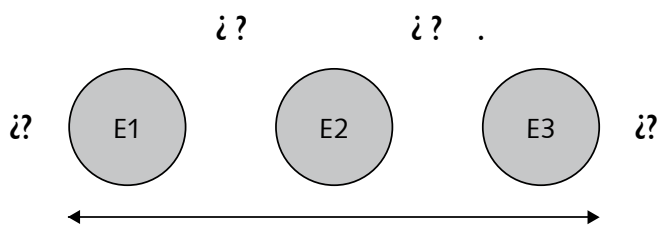

\footnotetext{
${ }^{20}$ Hegel, G.W.F., Principios de la filosofía del derecho, § 258, Agregado.

${ }^{21}$ Estas afirmaciones están contenidas en el texto de Žižek, "Lacan: at What Point is He Hegelian?”, en: Butler, Rex y Scott Stephens (eds.), Interrogating the Real, Londres: Continuum, 2005.
} 


\section{§ 2. Lacan y el sentido}

\section{$\S$ 2.I. Lacan y la reflexión lingüística}

Iniciemos mostrando el esquema saussureano del signo:

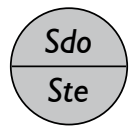

La noción de significante reemplaza a la imagen acústica y la de significado al concepto 22 .

Para Saussure: a) la langue es un sistema de signos y b) en la langue ( $y$ en cualquier sistema saussureano) solo hay diferencias (ningún elemento posee un valor propio, solo se caracteriza por "ser lo que los otros no son"23). La consecuencia inmediata de ambas afirmaciones es la siguiente: el signo solo tiene valor negativo. Sin embargo, Saussure asume que las diferencias se dan, por un lado, en el plano del significante $y$, por otro lado, por el del significado. De esta manera:

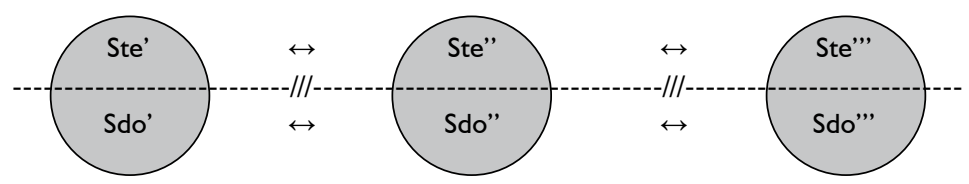

Entonces, si las relaciones de negatividad (diferencia) están del lado de los componentes del signo, este no puede ser, al mismo tiempo, un elemento negativo, es decir, no puede formar parte, tal cual, de la lengua. Hay dos soluciones a este problema: a) la langue no es un sistema signos b) en la langue no solo hay diferencias. De acuerdo a Mario Montalbetti, es el descubrimiento de esta falla y la elección de la primera solución la fundamentación del postulado lacaniano según el cual los elementos de la langue y, por ello, aquellos que establecen solo relaciones de negatividad, son únicamente los significantes. Lacan

${ }^{22}$ Saussure, Ferdinand de, Curso de lingüística general, traducción de Amado Alonso, Madrid: Alianza editorial, 1987, pp. 89-90. 
elimina del ámbito propio de la lengua al significado, el sistema está integrado por significantes cuya propiedad fundamental es ser lo que los otros no son ${ }^{24}$.

Hay una segunda formulación que se desprende la teoría de Saussure: la cuestión de la completud del sistema. Un sistema negativo requiere de por lo menos dos elementos, para que estos se opongan mutuamente, digamos A y $B$. Dados estos elementos tendremos que cada uno de ellos se define como -B y $-A$, respectivamente, entonces, aparecerá un elemento que deba ser tomado como-By-A que permita cerrar por completo el sistema (dar todas las relaciones posibles), pero este elemento necesariamente debe estar fuera del sistema, dado que indicamos que el sistema estaba conformado por dos elementos. Esta operación se reproduce ad infinitum ${ }^{25}$.

Estas dos revisiones parecen presupuestas en la teoría lacaniana y permiten entender su teoría del nudo borromeo y de los tres órdenes: imaginario, simbólico y real.

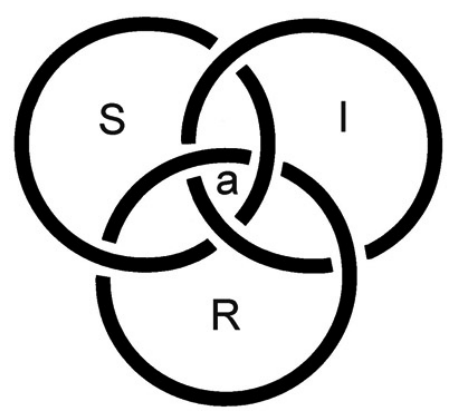

La lengua o, mejor dicho, la cadena significante (los significantes tienen otra propiedad fundamental: la de unirse uno con otro y formar cadena) es identificada con el orden simbólico, donde solo hay negatividad. El significado se asimila al orden imaginario y se asume como un efecto que producido a partir de la cadena significante a través de la operación del "punto de almohadillado"26,

${ }_{24}$ Montalbetti, Mario, Lacan arquitectura: notas del seminario, Lima: Fondo Editorial de la PUCP, 2009 , pp. 24 ss.

25 Ibid., pp. 33 y 34.

${ }^{26}$ Lacan, Jacques, Las psicosis 1955-1956: texto establecido por Jacques-Alain Miller, Barcelona:

Paidós, 1985, pp. 368-385 (sección “El punto de almohadilado"). 
a través del cual el sujeto "cierra" una cadena significante, colocando debajo de ella un significado.

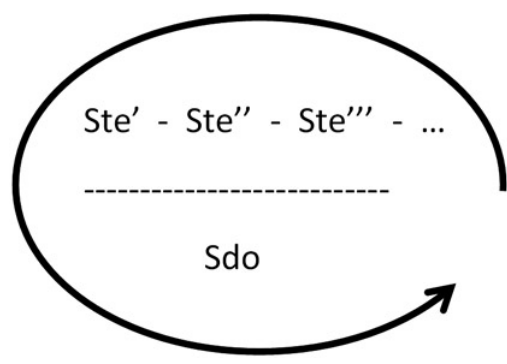

Finalmente, aquel elemento que continuamente es requerido para garantizar la completud del sistema pero que al mismo tiempo que aparece se hace necesario negar su pertinencia al mismo pertenece al orden de lo real. En todo sistema saussureano, siempre falta $u_{n o}^{27}$.

\section{§ 2.2. La noción de sentido}

Planteemos dos acepciones para el término "sentido" dentro de la obra de Lacan. La primera sitúa al sentido en la intersección de los órdenes simbólico e imaginario, intersección sumamente particular dado que el sentido es aquello que se ubica en la intersección de ambos sin pertenecer a ninguno de los dos. Esta primera acepción se vincula más con lo que normalmente entendemos por "sentido": algo tiene sentido si es entendible, si tiene lógica. Ello permite entender mejor la manera en que el sentido es "intersección": lo propio del sentido no es ni la pura negatividad en movimiento del simbólico ni la positividad estática del imaginario, sino el punto de reunión de ambos en que se produce la interpretación.

La segunda noción de sentido, que es la que aprovecharemos aquí, parte de una frase de Lacan en el Seminario XX: "le sens indique la direction vers laquelle il échoue” (el sentido indica la dirección hacia la que [él] falla) ${ }^{28}$. En Cajas, Mario

\footnotetext{
${ }^{27}$ Para mayores precisiones, consúltese el "Lexicon" incluido en el libro Lacan arquitectura de Montalbetti (pp. 196 ss.).

${ }^{28}$ Frase citada en Montalbetti, Mario, Cajas, Lima: Fondo Editorial de la PUCP, 20I2, no se indica 
Montalbetti explora esta definición y plantea una suerte de imagen explicativa que nos permite entender el sentido: el sentido es una caja ID.

Una caja es un objeto tridimensional que distingue adentro de afuera porque tiene un hueco adentro. Una caja promete un objeto dentro ("promete" porque el objeto no es visible, como lo sería si se tratase de una botella de vidrio). Esta es una caja 3D.

Si expandimos la caja (si mostramos el modelo bidimensional que da lugar a la forma cúbica), el objeto de la promesa debe encontrarse desplazado, fuera de la caja (para seguir siendo objeto de la promesa y para que esta siga siendo caja). Esta es una caja 2D. Las palabras pueden ser cajas de ambos tipos: si entendemos que el objeto de la promesa es la referencia, son cajas 2D (objeto fuera de ellas); si entendemos que lo es el "significado", son cajas 3D (objeto dentro de ellas).

¿Qué es una caja ID? Una caja ID es una caja cuyo objeto de la promesa no está ni dentro ni fuera de ella, sino que, de alguna manera es ella misma. Una caja ID, bajo la forma de una línea, no promete sino su propia expansión: aquí se vincula con el sentido. Sentido se distingue de dirección porque no promete nada externo a él (2D) o contenido en él (3D). El sentido es, en todo caso, la dirección en su versión más pura, infalible. ¿Por qué es falible una dirección? Es falible porque puede uno no encontrar lo prometido por ella. ¿Por qué es infalible el sentido? Porque no promete sino la dirección mostrada, que es imposible de no encontrar. Ahora, el sentido es infalible si se mantiene como tal pero se vuelve falible al encallar (échouer quiere decir, además de "fallar", "encallar"), al tomar una dirección determinada. En términos de Montalbetti, el sentido falla cuando deviene caja 2D o 3D.

Llegados a este punto, es pertinente preguntarnos iestán de algún modo vinculadas ambas acepciones de sentido? Señalamos que la primera asumía al sentido como consistencia, como inteligibilidad, y dicho fenómeno, en términos de lo conocido hasta aquí, indica cierta conexión con una dirección, con la posibilidad de la falibilización del sentido. Por lo tanto, podemos señalar 
que el primer "sentido" del que hablamos no es para nada identificable con el segundo. El sentido, precisamente, carece de "sentido". Vayamos ahora a uno de los ejemplos que encontramos de cajas ID, de sentido(s): la cadena significante.

Montalbetti dice: "Una cadena significante es puro sentido. Una cadena significante indica la dirección del despliegue de los significantes que la integran" y algunas páginas después: "Las cajas ID no existen en el mundo. La noción 'caja ID' no es una categoría ontológica sino formal”29

La cadena significante en tanto tal es un objeto problemático. Todo significante aparece en cadena, toda cadena aparece luego de la operación del punto de almohadillado. Presentar la cadena independientemente de dicha operación tampoco es posible, pues la estaríamos presentando finita, como si estuviésemos a punto de cerrarla (o como si ya la hubiésemos cerrado). Peor aún: es imposible presentar un significante: este solo aparece en cadenas. Pese a todo ello, podemos mostrar:

$$
\ldots \ldots \text { - Ste' - Ste" - Ste" - } \quad \ldots . .
$$

¿Qué mostramos cuando mostramos este esquema? Diríamos que mostramos la cadena significante. Pero no solo mostramos la cadena significante, mostramos, además, los significantes que la integran, los tomamos por objetos y los nombramos, eso nos lleva a la pregunta: el sentido, como caja ID, itiene elementos? Es esta la gran diferencia entre la formulación del sentido a partir de la línea como figura ID y los ejemplos que proporciona Montalbetti de cajas ID: la cadena significante, el muro, el deseo. Pareciera, pues, que el sentido debería entenderse autónomamente respecto a cualquier materialidad que lo "habite", ya sean los significantes, el concreto del muro o los decimales de 0,3333... (el símil del deseo que muestra Montalbetti). Un mejor símil del sentido es, por lo tanto, el que pone Lacan (no con las mismas intenciones) en las últimas páginas del Seminario III (Las psicosis): la autopista. 


\section{§ 2.3. La autopista}

"La carretera [autoroute], ese sí es un significante que merece ser tomado en cuanto tal” ${ }^{30}$, dice Lacan en la sesión del 28 de junio de 1956. Asumamos la autopista como metáfora del sentido. Una autopista no lleva de un punto a otro, un camino, una vía secundaria llevan de un punto a otro.

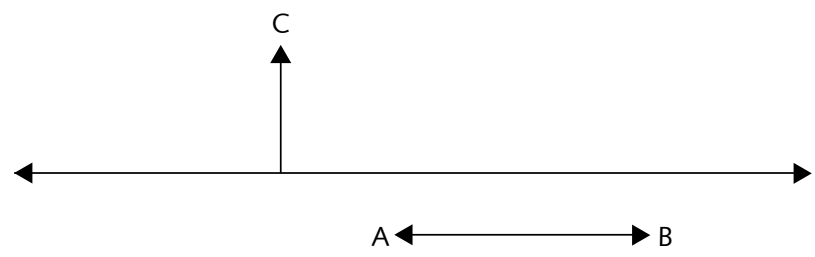

Una autopista es infalible (como el sentido) porque no promete nada salvo su propia dirección. La autopista se falibiliza cuando deviene camino, cuando tiene, al menos, un punto de llegada.

Volvamos a la pregunta anterior. Hay alguna distinción entre el sentido tal cualy aquellos elementos que "lo habitan". Lacan señala que no se puede "habitar" la autopista, las ciudades, las "aglomeraciones de significación” están construidas en los bordes de la autopista, se construyen casas sobre la autopista, pero no en la autopista. ¿De qué manera, entonces, los significantes habitan el sentido?

Para "ver" el sentido, hay que ver la autopista como si se viera pasar los vehículos a través de una ventana, sin verlos, ver solamente su fluir. Pero, evidentemente, no podemos "ver" el sentido, no podemos "ver" la cadena significante, menos aún los significantes. La metáfora se soporta hasta la oposición autopista/camino, pero su aplicación parece complicarse llegados a este punto. La única explicación que encontramos es que los significantes (o los vehículos) aparecen como necesarios en tanto ellos construyen el fluir pero lo construyen a fuerza de desaparecer en él, de dejar de ser vistos, la

\footnotetext{
${ }^{30}$ Lacan, Jacques, Las psicosis, pp. 406-419. Esta sección es comentada por Montalbetti en "Autopista, corredor y sentido". Ponencia presentada en el Tercer Seminario Binacional UCL/ PUCP DAR “Decir la arquitectura”, PUCP, 30 de octubre de 20I2; este texto así como una serie de conversaciones sostenidas con el autor nos fueron de gran ayuda.
} 
pregunta por ellos es posterior a la constitución del sentido, incluso es contraria a él, lo traiciona.

La constatación de que el sentido no es solo un fluir sino un fluir de es una manera de encallar. No podemos ver un significante sin hacer signo con él ("signo" sigue entendido aquí, pese a ya no ser el elemento del sistema de la langue, como la reunión entre significante y significado [este como efecto del anterior]), de este modo, no podemos ver un significante sin caer forzosamente en alguna significación particular. Pero no solo la vista de un significante único traiciona al sentido. La tesis de que el/un sentido está formado por tal o cual elemento es también una manera de encallar, una manera de insinuar la posibilidad de cierta dirección. Lacan introduce esta metáfora en parte para explicar el fenómeno del delirio del presidenteSchreber (el típico caso freudiano de psicosis) y coloca como significante primordial el significante ser padre ${ }^{3 !}$.

Encallar es, sin embargo, inevitable y necesario. No hay comprensión en el sentido (salvo en el definido primariamente), no se puede "habitar" la autopista. Quien "habita" la autopista es el psicótico, el sujeto que "ignora la lengua que habla" 32 , el sujeto no inscrito en el orden simbólico, el que ha forcluido el significante primordial del padre.

La idea del sentido, pero más claramente la de los significantes, es una idea límite, similar, como anota Montalbetti, a la idea wittgensteiniana de los objetos simples: estos son indiferenciables entre sí pero además, y sobre todo, son objetos de los que el propio Wittgenstein dice que no poseen propiedades ${ }^{33}$. Los significantes poseen algunas propiedades básicas: forman cadena, se relacionan negativamente, producen efectos. Pese a ello, nada se dice de su naturaleza misma, no se los "caracteriza" propiamente, el hecho de vincularlos con las palabras o con cualquier porción de discurso es inadecuado.

${ }^{31}$ Lacan, Jacques, Las psicosis, véase la sección “Introducción a la cuestión de las psicosis” (pp. II-28), en donde introduce el problema y hace referencia al caso freudiano del presidente Schreber y, en la sección “La carreterea principal y el significante ser padre”, véase la p. 416.

32 Ibid., p. 73.

${ }^{33}$ Wittgenstein, Ludwig, Wittgenstein. 2 v., Madrid: Gredos, 2009, vol I, ver proposición 2.02 ss., p. 13 ss. 
El sentido está formado por ciertas unidades: los significantes. No sabemos qué son (a qué género pertenecen) los significantes. Cualquier definición, quizá incluso la negatividad y el encadenamiento, pasa por inadecuada, pero aun así hablamos de ellos, como Wittgenstein y sus simples; también hablamos de algo así como el sentido. Hablemos ahora de un sentido, un sentido en el cual hemos encallado (inevitablemente) de manera voluntaria: el sentido ético.

Montalbetti titula su conferencia "Autopista, corredor y sentido" y en ella muestra los vínculos entre este símil de la autopista, el sentido y la arquitectura, llegando a la figura del corredor. A partir de ello, podemos pensar al sentido y sus encallamientos como una especie de función lógica o de fractal. El sentido es uno, este encalla, cuando encalla puede generar sentidos (ivinculados con la primera acepción?) dentro de las aglomeraciones de significación que fueron producto de la primera falla. La autopista encalla en carreteras secundarias, las carreteras secundarias encallan en caminos, estos en calles, estas, en corredores en las casas, etc (o no).

\section{§ 3. El sentido ético}

Una manera de encallar es la ética. La ética es una manera de encallar.

La sección anterior nos permitió llegar, con todas las preguntas pendientes, al sentido buscado al final de nuestra exposición del problema de la teleología en la filosofía del espíritu objetivo de Hegel. Hablaremos ahora de una de las maneras como el sentido (concepto límite) encalla.

\section{§ 3.I. La función sentido}

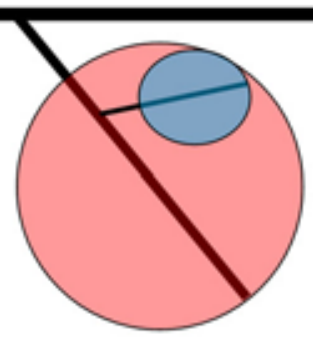


Imaginemos que la línea más gruesa es el sentido del que hemos estado (contradictoriamente) hablando. Este encalla en la dirección de la línea de grosor medio y forma una aglomeración de significaciones: el círculo rojo (ese es el punto de llegada, el signo). Dentro del círculo rojo (dentro de un discurso particular, digamos), se identifica, al mismo tiempo cierto sentido, libre en principio de significados y quizá no conocido actualmente en su dimensión de sentido (digamos, el término "democracia”). El sentido "democracia" (cualquier acción de nombrar es conscientemente traidora a la definición original) encalla nuevamente y forma una nueva aglomeración de significaciones: el círculo azul (digamos "democracia liberal”), eventualmente en dicho círculo podrá notarse un nuevo sentido, etc.

Varias preguntas surgen a partir de esta recursividad del sentido, a riesgo (o no) de una ontologización del mismo.

I) iSon los subniveles infinitos?

2) ¿Hay un nivel (el sentido) de donde provengan todas las subdivisiones?

3) ¿Qué posición ocupa el sujeto en el gráfico?

Para empezar descartemos una intuición que posiblemente surja a partir del gráfico: el saber humano está organizado jerárquicamente, el sentido (aún como lo entendemos) posee la mayor jerarquía y en base a él surgen las determinaciones particulares. El mayor peligro de esta intuición es que puede derivar en la pregunta por la meta de dicho saber humano. No hay tal necesidad: los subniveles de los que hablamos deben plantearse como modelo interpretativo en ámbitos bastante delimitados, en los cuales se percibe cierta aglomeración de significaciones que falla en el sentido fuerte, es decir, cuya promesa se vuelve insostenible.

La aplicación de lo que podemos denominar "la función sentido" muestra a un determinado discurso en su dimensión de aglomeración de significaciones, nos pone frente al nivel superior por un momento y nos trae de vuelta: es una posibilidad de crítica. De esta manera, no dependemos de que haya o no haya un último nivel, en todo caso, podemos presuponerlo, de hecho necesitamos presuponerlo para entender lo que debería ser el nivel al que recurrimos. No se puede "habitar" el sentido, habría que preguntarnos nuevamente si el psicótico realmente "habita" el sentido. 
La primera interrogante presupone que haya un primer sentido, desde el cual se empiezan a contar los subniveles.

La tercera pregunta está conectada con la segunda. El sujeto requiere de un sentido falibilizado, requiere habitar un lenguaje con significado y con consistencia (la primera acepción de "sentido"), el sujeto habita en alguna aglomeración de significaciones. Esta aglomeración puede crear la figura de un sentido que sea interior a ella; como en el ejemplo de la democracia, podemos asumirla como un significante vacío (como lo hace Žižek) y mostrar desde ahí otras sub-aglomeraciones. Algo es cierto: nunca saldremos a la autopista. Las salidas parciales dan sentido al discurso en todas sus dimensiones: la ética es una salida.

\section{$\S$ 3.2. El sentido de la ética}

Dejemos a un lado la pregunta por aquella autopista en función de la cual la ética es una salida. Entendamos la salida ética como autopista. La ética tiene, entonces, sus propias salidas. ¿Cuáles?

Las salidas de la ética son, en primera instancia, los sistemas éticos, entendidos en su dimensión de totalidad. El Estado como lo entiende Hegel es una salida de la ética. Es necesario que aparezca la idea de totalidad, una aglomeración es un sistema cerrado, tiene un componente del orden imaginario; un sistema con relaciones puramente negativas no es una salida de la ética (tal como la estamos entendiendo): una sociedad kantiana pura (es decir, una que no ha sustancializado las máximas universales [los DD. HH. no son un mal ejemplo aquí]) no es una salida de la ética, una polis aristotélica sí. La salida ética requiere de este contenido sustancial para ser realmente signo.

Pero hay otro tipo de salidas de la ética: las teorías sobre la ética. Una teoría sobre la ética le pone un nombre al significante que falta: eudaimonía, autonomía, bien; busca encontrar el sentido del sentido, volverlo dirección. La diferencia con las salidas anteriores es que, si bien un sistema ético puede pretenderse absoluto (no digamos "universal"), no plantea una comprensión de la ética como fenómeno, una teoría sobre la ética sí, busca encontrar algún telos. Lacan, en el Seminario VII (La ética en el psicoanálisis), menciona el modo en que Kant desplazó por completo el significante "bien" (Gut) alejándolo por completo del "bienestar" (Wohl). El bien para Kant ( $y$ tal como lo entiende Hegel en la 
moralidad) es el nombrar por excelencia del final del sentido ${ }^{34}$. Por otro lado, las teorías sobre la ética dicen algo, además, sobre las otras salidas de la ética, describen a los sistemas éticos en base a criterios que ellos plantean: utilidad, universalidad de las normas, felicidad, acuerdo, etc. Podríamos decir, también, que una teoría sobre la ética plantea un camino paralelo a la autopista que permite llegar de un sistema ético a otro pero pretendiendo ser el camino, pretendiendo hacer las veces de la autopista.

Toda teoría sobre la ética es una teoría sobre el sentido del sentido ético y sobre las salidas del mismo, pese a ello, es también una salida. Evidente e inevitable paradoja.

Volvamos a nuestro gráfico anterior:

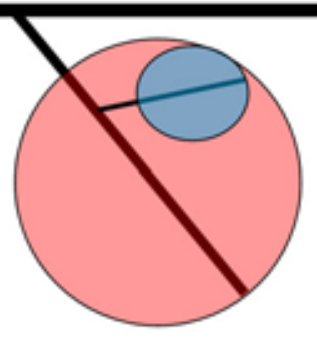

Digamos que el círculo azul es un sistema ético determinado, la línea que le es interior es uno de esos sentidos que solemos descubrir como tales dentro de nuestro propio discurso. La línea roja es la salida ética (el sentido de la ética). El círculo rojo es la teoría sobre la ética, digamos, desde un punto de vista imaginario: ella pretende encerrar la línea roja y delimitarla, de esa manera, dice algo de ella; pero además dice algo de las aglomeraciones que le son internas, como el círculo azul, tanto de cada una de ellas como del conjunto.

Asumamos que el círculo rojo es la filosofía práctica de Hegel. Esta, como hemos detallado antes, pretende dar cuenta del desarrollo del espíritu hasta su autoconocimiento, dentro de él, el espíritu objetivo deviene históricamente (línea roja) y forma realidades institucionales: los Estados (círculo azul), los cuales

${ }^{34}$ Lacan, Jacques, The Seminar of Jacques Lacan. Book VII. The Ethics of Psychoanalysis 1959-1960, traducción de Dennis Porter. Nueva York / Londres: Norton \& Company, 1992, pp. 7I-84. 
son organismos completamente individuales. La teoría de Hegel muestra una lógica en la constitución interna de estos organismos pero también pretende decir algo del sentido del sentido del espíritu objetivo: este se consolida en los Estados y da paso a la historia universal, como terreno del espíritu absoluto.

En la primera parte del texto exploramos una suerte de paradoja que surgía del estudio de la supuesta teleología del espíritu objetivo, de la realización de la finalidad de este en su propio ámbito. Volvamos a ello.

$\rightarrow$ No diremos nada aún sobre el círculo blanco.

\section{§ 3.3. Hegel y Lacan (a modo de conclusión)}

Nuestra exploración de la teoría lacaniana del sentido obedecía a la necesidad de hallar una lógica que soporte el recorrido del espíritu objetivo y que no implique una realización del telos en su propio ámbito. Creemos que el sentido ético puede dar una respuesta.

El sentido ético y las consecuencias que hemos extraído de él, relativas a los tipos de salida que muestra, determinan una comprensión distinta de la teoría hegeliana. Esta, forzosamente, es una de esas salidas, pero tiene algo de particular: su telos. El espíritu absoluto, despojado de su carácter metafísico y reducido a la sola idea de la falta del otro invita precisamente a contemplar el fluir de momentos en la historia, la sucesión de realidades éticas (las cuestiones institucionales pueden cuestionarse) sin una dimensión de consumación más allá de la propia conciencia de la falta.

Volviendo a la analogía inspirada en el gráfico: El círculo rojo hegeliano encalla en un nombre: el absoluto, que termina no diciendo sino el puro señalamiento de la inexistencia de una concreción última. No hay un último Estado, la historia no termina en la dimensión del espíritu objetivo. El espíritu objetivo, el conjunto de salidas éticas se abre hacia el pensamiento del absoluto que no es más que la puesta en evidencia de la imposibilidad de un cierre, ver el absoluto no es ver una cosa, no verlo es tratar de ver la cosa (Das Ding). Debemos, entonces reconfigurar el gráfico: 


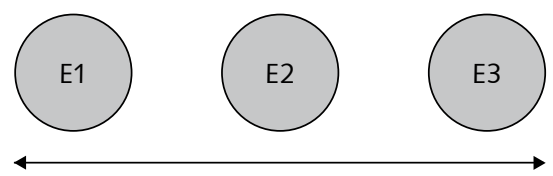

SENTIDO ÉTICO

Pero los Estados (las totalidades éticas) son las aglomeraciones de significación, ¿cuáles son los significantes? ¿Qué fluye en el sentido ético? La pregunta nos lleva a reconfigurar el gráfico:

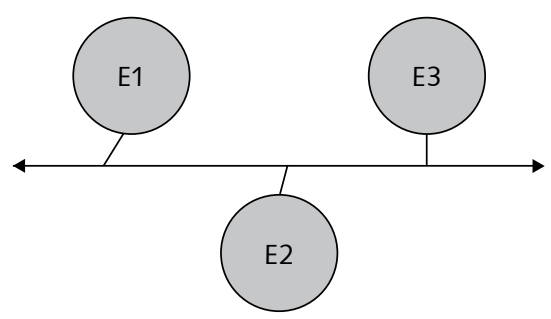

Aquello que fluye no son las totalidades éticas sino algo así como los significantes éticos. Pero conocer los significantes éticos implicaría, en principio concebirlos ya como signos, como aglomeraciones y, por ello, implicaría también rozar la pregunta que dejamos de lado al inicio de la sección anterior: si la ética es una salida ¿cuál es la autopista?

Para nuestros fines debemos limitarnos a constatar la existencia de cierto sentido en la ética y a dar cuenta de él a través de sus efectos. Este sentido ético es tanto diacrónico como sincrónico: se lo puede entender en diversos planos, tal como se puede entender, creemos, el espíritu objetivo hegeliano.

El sentido ético nos otorga la lógica del espíritu objetivo, su retorno hacia el absoluto. Lo absoluto no es una fase del espíritu: es el espíritu

$\rightarrow$ Nunca diremos nada del círculo blanco (Proposición 7 del Tractatus) ${ }^{35}$ 